\title{
ESTUDO EVOLUTIVO DE FÍSTULAS NA DOENÇA DE CROHN
}

\author{
Flavio STEINWURZ*
}

RESUMO - Foram estudados 16 pacientes portadores de doença de Crohn com fístulas. A evolução de 29 fistulas, nestes casos, 10 tratadas por cirurgia e 19 através de medicamentos, foi acompanhada quanto à cicatrização e melhora do processo.

\author{
DESCRITORES - Fístula. Doença de Crohn.
}

A doença de Crohn ainda é um desafio para os médicos e parece mostrar em todo o mundo uma tendência de aumento na sua incidência.

Evidentemente que esta elevação nas estatísticas da moléstia, levou os gastroenterologistas a pesquisas mais apuradas no sentido de obter um melhor controle da doença e de suas complicações, já que sua causa e cura continuam desconhecidas.

Uma das complicações mais inconvenientes para os portadores é a fístula, comunicação anômala de órgãos ou estruturas através de um pertuito anormal. Pode ser interna, entre órgãos intracavitários (interalças, enterovesical, enterovaginal, etc), ou se exteriorizar (fístula perianal, enterocutânea ou de parede abdominal, etc.)

Além do aspecto fisiopatológico, de perda de nutrientes, dor, desconforto e infecção, a fístula pode causar constrangimentos quando com drenagem aparente abundante.

No passado, a abordagem terapêutica para tais lesões era exclusivamente cirúrgica. Mais recentemente, com a experiência obtida, principalmente através do uso de drogas imunossupressoras, o tratamento clínico vem ganhando espaço.

\section{OBJETIVO}

Avaliar a evolução de fístulas em 16 pacientes portadores da doença de Crohn observados na década de 90 e submetidos a algum tipo de tratamento, clínico ou cirúrgico.

\section{CASUÍSTICA}

Dezesseis pacientes de nossa clínica privada, portadores de doença de Crohn e com a presença de fístulas comprovadas por exame clínico e/ou radiológico foram estudados quanto à evolução das mesmas.

As fístulas foram relacionadas de acordo com o tipo, localização e quanto ao procedimento terapêutico adotado.

O tratamento cirúrgico se fez através de fistulectomia ou ressecção de alças com fístulas. O tratamento clínico foi feito

* $\quad$ Mestre em Gastroenterologia pelo IBEPEGE. Fellow do American College of Gastroenterology. Presidente da ABCD - Associação Brasileira de Colite Ulcerativa e Doença de Crohn.

Endereço para correspondência: Dr. Flavio Steinwurz - Rua da Consolação, 3741 - $7^{\circ}$ andar - 01416-001 - São Paulo, SP. 
através do uso de drogas imunossupressoras, em especial a 6-mercaptopurina em dose de 50 a $100 \mathrm{mg}$ por dia, por períodos nunca inferiores a três meses; ou infliximab (anticorpo monoclonal anti fator de necrose tumoral $\alpha$ ) em três séries conforme orientação do fabricante.

Todos os pacientes foram acompanhados por um período superior a um ano, com exceção dos tratados com infliximab, cuja observação ocorreu por apenas seis meses.

Julgamos a evolução do tratamento de acordo com a observação clínica e por meio de exames específicos, por exemplo, exames ginecológicos em fístulas enterovaginais, $\mathrm{Rx}$ do trânsito intestinal em fístulas interalças, etc.

Consideramos cicatrizadas, as fístulas que não apresentavam qualquer fluxo residual e que tinham completo fechamento do orifício no caso de visualização do mesmo.

Relatamos casos com melhoria, todos aqueles em que houve uma significativa redução do volume drenado pela fístula e diminuição do orifício exteriorizado. Chamamos de inalterado aqueles que não mostraram qualquer mudança para melhor naquele processo.

\section{RESULTADOS}

Dos 16 pacientes portadores da doença da Crohn com fístulas, oito eram do sexo masculino e oito do feminino.

Entre as oito mulheres havia um total de 14 fístulas, ao passo que os oito homens apresentavam 15 .

As fístulas encontradas puderam ser divididas da seguinte maneira:

- interalças - $2(6,9 \%)$
- enterovaginal - $5(17,2 \%)$

- perianal - $7(24,1 \%)$

- enterocutânea - 15 (51,7\%)

(Observação: O número de fístulas é maior que o número de pacientes pois um mesmo paciente podia apresentar mais de uma fístula).

Do total de 29 fístulas, 10 foram tratadas cirurgicamente, enquanto 19 o fizeram com medicamentos. Optamos por avaliar fístulas tratadas e não pacientes, pois havia casos de pacientes tratados cirurgicamente para um tipo de fístula e clinicamente para outro.

Com relação as 10 fístulas tratadas com procedimento cirúrgico, $60 \%$ foram resolvidas e $40 \%$ tiveram recidiva no mesmo local, ou na zona de incisão cirúrgica, num período de até um ano.

Dezessete das 29 fístulas foram tratadas com 6-mercaptopurina e duas com anticorpo monoclonal anti-fator de necrose tumoral- $\alpha$ (infliximab).

Dez delas $(52,6 \%)$ cicatrizaram completamente e quatro $(21,0 \%)$ tiveram melhora (três enterovaginais e uma perianal).

Três não tiveram benefícios com 6 mercaptopurina. (As duas fístulas tratadas com infliximab cicatrizaram).

\section{DISCUSSÃO}

As fístulas são complicações que aparecem com certa freqüência em portadores da doença de Crohn. No presente momento, ainda não há um tratamento específico que possa resolvê-las, promovendo completa cicatrização em todos os casos.

Em nossa observação de 16 pacientes portando 29 fístulas, verificamos que naqueles submetidos a tratamento clínico houve melhora num percentual ligeiramente maior, com concomitante alívio no quadro clínico e atividade da doença. Isto se deu sem que nestes casos houvesse efeitos colaterais mais sérios (apenas leucopenia no uso de 6mercaptopurina, controlada com a redução na dosagem da droga).

A 6-mercaptopurina mostrou, em nossos casos, ser uma droga eficaz em melhorar e/ou cicatrizar as fístulas em portadores da doença de Crohn, o que está de acordo com a literatura especializada $^{(4,6,7,9)}$.

As duas fístulas tratadas com infliximab tiveram resolução completa, mostrando sua eficácia como o descrito em outros trabalhos científicos $^{(8)}$

A literatura mostra, também, resultados promissores com uso de outras drogas e procedimentos para cicatrização de fístulas, tais como ciclosporina (EV), metronidazol, methotrexate e oxigenoterapia hiperbárica ${ }^{(1,2}$, ${ }^{3,5)}$. Nenhuma foi por nós utilizada nos pacientes em questão, razão pela qual não foram citadas nos resultados.

\section{CONCLUSÃO}

O tratamento clínico é eficaz para o controle de fístulas na doença de Crohn. Mostra índices de resolução similares ao tratamento cirúrgico com baixa incidência de efeitos colaterais e melhora concomitante do quadro da doença.

Acreditamos, portanto que, a princípio, a tentativa de melhoria clínica da fístula deve ser utilizada, desde que haja condições para tal. Deve-se, então, deixar a opção cirúrgica para os casos onde ocorra insucesso da terapêutica medicamentosa, ou quando existir associação com outra complicação, tal como abscesso ou infecções. 
Steinwurz F. A follow-up study of fistulae in Crohn's disease. Arq Gastroenterol, São Paulo, 36(4):207-209, 1999.

ABSTRACT - Sixteen Crohn's disease patients with fistulae were studied. They had overall 29 fistulae, 10 treated surgically and 19 with drugs, which were followed regarding to the healing and improvement of the process.

HEADINGS - Fistula. Crohn disease.

\section{REFERÊNCIAS BIBLIOGRÁFICAS}

1. Brady CE, Cooley B, Davis JC. Healing of severe perineal and cutaneous Crohn's disease with hyperbaric oxygenation. Gastroenterology, 97:756, 1989.

2. Brandt LJ, Bernstein LH, Boley S, Frank MS. Metronidazole therapy for perineal Crohn's disease. A follow up study. Gastroenterology, 79:357, 1980 .

3. Hanauer SB, Smith MD. Rapid clousure of Crohn's disease fistula with continuous intravenous cyclosporine. Am J Gastroenterol, 88:646, 1993.

4. Korelitz BI, Present DH. Favorable response of 6-mercaptopurine on fistula of Crohn's disease. Dig Dis Sci, 30:58, 1985.

5. Kozarek RA, Patterson DJ, Gelfand MD, Botoman VA, Wilske KR. Methotrexate induced clinical and histologic remission in patients with refractory inflammatory bowel disease. Ann Intern Med, 110:353, 1989.

6. O'Brien JJ, Bayless TM, Bayless JA. Use of azathioprine or 6mercaptopurine in the treatment of Crohn's disease. Gastroenterology, 101:39, 1991.

7. Present DH, Korelitz BI, Wisch N, Glass JL, Sachar DB, Pasternack BS. Treatment of Crohn's disease with 6-mercaptopurine. A long term randomized double blind study. N Engl J Med, 302:981, 1980.

8. Present DH, Mayer L, van Deventer SVH, Rutgeerts P, Hanauer S, De Woody TK, Braakamn T, Schaible T, CA2 Study Group. Anti TNF alpha chimeric antibody (cA2) is effective in the treatment of the fistula of Crohn's disease. Am J Gastroenterol, 92:1746, 1997. [Abstract A648].

9. Wheeler SC, Marion JF, Present DH. Medical therapy, not surgery, is the appropriate first line of treatment for Crohn's entero-vesical fistula. Gastroenterology, 114:A1113, 1998. [Abstract]. 